\title{
Rancang Bangun Mesin Pengolah Limbah Kain dan Kertas Sebagai Bahan Industri Eternit
}

\author{
Moh. Dahlan*), Rochmad Winarso, Sugeng Slamet \\ Jurusan Teknik Elektro, Fakultas Teknik, Universitas Muria Kudus, Kampus UMK Gondangmanis \\ PO.BOX 53, Kudus
}

\begin{abstract}
Abstrak
Di Kabupaten Kudus, saat ini berkembang UMKM dalam usaha pembuatan eternit. Bahan baku pembuatan eternit terdiri ini terdiri dari semen dan serat kain. Disatu sisi, di Kabupaten Kudus banyak tumbuh sentra-sentra industri garment seperti di desa Langgar Dalem, Loram Wetan, Loram Kulon, Megawon, Klumpit, Undaan dan masih banyak lagi yang menghasilkan limbah kain tidak termanfaatkan. Untuk itu diperlukan inovasi dalam memanfaatkan bahan baku yang melimpah tersebut guna memenuhi UKM pembuatan eternit. Tujuan dari penelitian ini adalah merancang bangun mesin pengolah limbah kertas dan kain menjadi bahan baku eternit untuk produksi UKM eternitdengan kapasitas 1200 gr/putaran. Tenaga penggerak menggunakan motor listrik 6 PK, 3 phase putaran $1400 \mathrm{rpm}$, sehingga kapasitas maksimal mesin crusher sebesar $120 \mathrm{~kg} / \mathrm{jam}$. Metode yang digunakan dalam penelitian ini adalah: 1) melakukan survey ketersediaan bahan baku berupa sampah kain/kertas, serta menganalisa kualitas serat penguat bahan baku. 2) merancang desain dari mesin pengolah limbah kain/kertas, 3) menentukan kebutuhan komponen serta kesiapan laboratorium pendukung yang akan digunakan untuk membuat mesin tersebut. 4) pengujian mesin yang telah dirancang. Telah dirancang mesin pengolah limbah kertas dan kain dengan kapasitas mesin crusher sebanyak 1200 gr/putaran, sebagai bahan baku eternity untuk meningkatkan kapasitas produksi industry eternit. Direncanakan kemampuan tenaga penggerak menggunakan motor listrik 6 PK, 3 phase putaran 1400 rpm, sehingga kapasitas maksimal mesin crusher sebesar $120 \mathrm{~kg} / \mathrm{jam}$.
\end{abstract}

Kata kunci: limbah; industri eternit; pengolah kain dan kertas

\begin{abstract}
[Title: Machine Design of Cloth Fiber and Paper Wastes Conversion to Plasterboard]. Nowadays, UMKM industry producing plasterboard has been being developed in Kudus regency. The raw material used in producing plasterboard consists of cement and cloth fiber. On the other hand, there are also many garment industries developed in Langgar Dalem, Loram Wetan, Loram Kulon, Megawon, Klumpit, Undaan and many more which result in cloth waste. Therefore, innovation is needed to make use of those abundant raw material in order to fulfil the need of UKM in producing plasterboard. This research is aimed at designing a model of a processor machine for processing cloth and paper waste into basic material for producing plasterboard, with capacity of $1200 \mathrm{gr} /$ round. This machine's propulsion uses 6 PK elcetric motor, 3 round phases 1400 rpm, so that the maximum capacity of the crusher machine will be $120 \mathrm{~kg} /$ hour. The research methods used are: 1) doing survey on raw material supply, includes cloth or paper waste, and analysing the quality of their fiber; 2) designing a model of a processor machine for cloth and paper waste; 3) determining what components are needed as well as the the readiness of supporting laboratory which will be used to build the machine; 4) testing the machine once it is built. This machine is used as a basic tool to produce plasterboard. With this machine, it is expected that the plasterboard production will increase significantly. This machine's propulsion is designed to use 6 PK electric motor, 3 round phases 1400 rpm, so that the maximum capacity of the crusher machine will be $120 \mathrm{~kg} / \mathrm{hour}$.
\end{abstract}

Keywords: waste; plasterboard industry; cloth and paper processing

\section{Pendahuluan}

${ }^{*}$ Penulis Korespondensi.

E-mail: dahlan.kds@gmail.com
Sehubungan dengan penelitian-penelitian sebelumnya tentang pemanfaatan limbah kain dan kertas rata-rata masih dimanfaatkan dalam bentuk kerajinan, perlu diketahui setiap hari jumlah sampah kertas dan kain semakin bertambah sesuai 
Teknik, 37 (1), 2016, 2

dengan bertambahnya kebutuhan manusia, untuk itu kami mencoba memanfaatkan sampah ini untuk kebutuhan secara teknis lebih bermanfaat.

Di Kabupaten Kudus, saat ini berkembang UMKM dalam usaha pembuatan eternit. UMKM ini kebanyakan terletak di Desa Getas Pejaten, kurang lebih $7 \mathrm{~km}$ dari pusat kota. Dari pengamatan di lapangan, pekerjaan pembuatan eternit ini dari sisi teknologi masih mempergunakan teknologi sederhana dan dan kurang efektif dari sisi optimalisasi industry sehingga mempunyai produktifitas yang rendah. Rata-rata hasil produksi 80-90 lembar per hari dengan waktu kerja 8 jam.

Bahan baku pembuatan eternit terdiri ini terdiri dari semen, serat kain, mill dan oli bekas. Sedang mesin produksi yang ada hamper semua bersifat sederhana dan konvensional, hanya berupa silinder rol penggilas yang berfungsi juga sebagai penekan. Untuk mencampur (mixer) bahan baku seperti semen, mill, serat kain, dan oli dengan cara membuat kubangan dan diaduk dengan sekop. Untuk pengeringan masih menggunakan sistem alamiah yaitu di tiriskan pada udara panas dari sinar matahari. Disamping mesin produksi yang masih konvensional, keterbatasan bahan baku serat penguat menjadi kendala utama untuk meningkatkan kapasitas produksi. Selama ini serat limbah kain yang di datangkan dari beberapa pabrik tekstil di wilayah lain.

Disatu sisi, di Kabupaten Kudus banyak tumbuh sentra-sentra industri garment seperti di desa Langgar Dalem, Loram Wetan, Loram Kulon, Megawon, Klumpit, Undaan dan masih banyak lagi yang menghasilkan limbah kain tidak termanfaatkan. PT. Colombo dan PT. Muriatex merupakan pabrik tenun yang menghasilkan kain limbah/reject rata-rata $10 \%$ dari total produksinya, sehingga dilihat dari bahan baku sebetulnya di Kabupaten Kudus sendiri sangat melimpah, tetapi hal ini sampai saat ini belum termanfaatkan dengan optimal

Kebaruan dari penelitian ini adalah; pemanfaatan bahan limbah dari lokal (konveksi dan industri tekstil) untuk pemenuhan kebutuhan bahan baku UMKM lokal (industri eternit di wilayah Kudus) sekaligus mengurangi dampak lingkungan, diistilahkan; "Zero Wasted from Local to Local for Green Environment”.

Sehingga sangat memungkinkan terjadinya kemitraan antara usahawan garment, pengumpul limbah kertas dengan usaha pembuatan eternit ini. Tentunya hal ini harus didukung teknologi pengolah limbah kertas/kain untuk dijadikan serat sebagai bahan baku utama pembuatan eternit. Mesin pengolah limbah kain/kertas sebagaimana kami sebut diatas, belum dipunyai oleh industri pembuatan eternit ini. Padahal kebutuhan serat kain/kertas cukup tinggi 300-350 kg perhari dengan harga beli Rp 5000/kg. Permintaan pasar untuk memenuhi pesanan beberapa toko bangunan yang ada di Kudus, Demak, Jepara, Pati dan Grobongan bisa mencapai $\pm 1000 \mathrm{~kg}$ per hari. Sementara kemampuan produksi maksimal $400 \mathrm{~kg}$ per hari.

Kualitas produk eternit sangat ditentukan oleh kekuatan tekan dan densitas/kerapatannya. Hal ini sangat bergantung dengan kekuatan serat penguat serta komposisi bahan utama. Rendahnya kualitas produk di UKM Mitra lebih banyak disebabkan oleh kedua hal tersebut yaitu kualitas serat penguat yang rendah serta prosentase serat yang kurang.

Limbah kain/kertas yang dipandang kurang mempunyai manfaat dan banyak dijual murah sebagai produk sampah, dapat diolah untuk bahan baku berupa serat penguat untuk pembuatan eternit. Melalui teknologi pengolah limbah kain/kertas menjadi serat penguat eternit inilah yang sangat diharapkan oleh usaha kecil menengah sebagai bahan baku pembuatan eternit, sehingga kapasitas produksinya meningkat.

Dengan penerapan dan pengembangan teknologi pengolah limbah kain/kertas ini, UKM akan mampu meningkatkan kapasitas produksi sehingga dapat memenuhi permintaan pasar yang pada akhirnya meningkatan pendapatan. Dapat menumbuh kembangkan jiwa berwiraswasta, serta penyerapan tenaga kerja. Disamping itu, dengan pemanfaatan limbah kain/kertas sebagai bahan baku serat juga mengatasi permasalahan sampah dan pencemaran lingkungan.

Selama ini serat penguat untuk bahan baku pembuatan eternit diperoleh dari limbah kain pabrikan. Serat kain ini jumlahnya terbatas dan harganya relatif mahal. Teknologi mesin pengolahan limbah kain/kertas belum dapat diusahakan oleh industri menengah kecil karena harganya yang relative mahal. Mesin ini dirancang sederhana tanpa mengurangi kemampuan dan kualitas produksinya.

Dampak positif yang timbul dari penerapan dan pengembangan teknologi ini adalah mengatasi permasalahan limbah bagi lingkungan, terutama limbah kain dan kertas, disamping itu penyerapan tenaga kerja melalui unit usaha baru pengolahan limbah kain/kertas, menumbuhkan wirausahawan baru, tumbuhnya kemitraan antar pengusaha.

Tujuan dari penelitian ini adalah; merancang bangun mesin pengolah limbah kertas dan kain menjadi bahan baku eternit untuk produksi UKM eternit dengan kapasitas 1200 gr/putaran. Tenaga penggerak menggunakan motor listrik 6 PK, 3 phase putaran $1400 \mathrm{rpm}$, sehingga kapasitas maksimal mesin crusher sebesar 120 $\mathrm{kg} / \mathrm{jam}$.

\section{Bahan dan Metode}

Mesin crusher limbah kain menjadi serat untuk penguat bahan komposit ini terdiri atas: (a) 
Teknik, 37 (1), 2016, 3

Pisau dinamis sebanyak 9 baris $\mathrm{x} 3$ buah $=27$ buah; dan (b) Pisau statis sepanjang $300 \mathrm{~mm}$ sebanyak 9 buah. Dengan spesifikasi pisau diatas diharapkan kapasitas maksimal mesin crusher sebesar 120 $\mathrm{kg} / \mathrm{jam}$. Adapun dimensi pisau sebagimana ditunjukkan pada Gambar 1.

Bahan pisau/tool steel dipilih baja paduan antara unsur Carbon (C) dengan paduan Cr, W, Mo dan V sesuai untuk baja perkakas (Malau, 2004). Dalam perancangan ini material pisau menggunakan baja special $\mathrm{K}$ dengan proses pengerasan hardening sebagai berikut : Suhu hardening 950-980 ${ }^{\circ} \mathrm{C}$ untuk mencapai kekerasan 63-65 HRC Media quenching oli atau udara. Untuk mencapai suhu $950{ }^{\circ} \mathrm{C}$ harus dipanaskan bertahap yaitu: (1) Suhu $450{ }^{\circ} \mathrm{C}$ ditahan selama 10 menit / 10 $\mathrm{mm}$ tebal material; (2) Lalu dipanaskan lagi ke 750 ${ }^{\circ} \mathrm{C}$ selama 10 menit / $10 \mathrm{~mm}$ tebal material; (3) Lalu dipanaskan kembali sampai suhu $950-980{ }^{\circ} \mathrm{C}$; (4) Di tahan sebentar lalu di keluarkan dan di celupkan kedalam oli quenching sambil digoyang goyang supaya gelembung asap cepat terlepas dari permukaan baja sehingga pendinginannya dapat merata (Hendro, 2011).
Kapasitas produksi sangat dipengaruhi juga oleh sifat fisis daripada jenis kain yang dihancurkan. Nilai berat jenis kain sangat beragam ${ }^{[4]}$ sebagai berikut :

- Berat jenis serat kapas 1,4905 gr/ $\mathrm{cm}^{3}$

- Berat jenis Rayon Viskosa $1,527 \mathrm{gr} / \mathrm{cm}^{3}$

- Berat jenis Rami 0,97795 gr/ $\mathrm{cm}^{3}$

- Berat jenis Sutera 1,2715 gr/ $\mathrm{cm}^{3}$

- Berat jenis Wool 1,3445 gr/ $\mathrm{cm}^{3}$

- Berat jenis Poliester $1,3445 \mathrm{gr} / \mathrm{cm}^{3}$

- Berat jenis Poliaklirat $1,0525 \mathrm{gr} / \mathrm{cm}^{3}$

- Berat jenis Poliamida 1,125 gr/ $\mathrm{cm}^{3}$

- Berat jenis Poliester-Kapas 1,4905 gr/ $/ \mathrm{cm}^{3}$

- Berat jenis Poliester-Rayon 1,4905 gr/ $/ \mathrm{cm}^{3}$

- Berat jenis Poliester-Wool 1,4175 gr/ $\mathrm{cm}^{3}$

Adapun sisi mata potong pada pahat mempunyai $15 \mathrm{~mm}^{3}$ sama artinya dengan volume serat kain yang terpotong. Massa serat kain dengan memilih salah satu jenis serat kain misalnya serat kapas $\rho=1,49 \mathrm{~g} / \mathrm{cm}^{3}$ maka didapatkan kapasitas mesin crusher sebanyak $1200 \mathrm{gr} /$ putaran. Tenaga penggerak menggunakan motor listrik $6 \mathrm{PK}, 3$ phase putaran $1400 \mathrm{rpm}$, sehingga kapasitas maksimal mesin crusher sebesar $120 \mathrm{~kg} / \mathrm{jam}$.

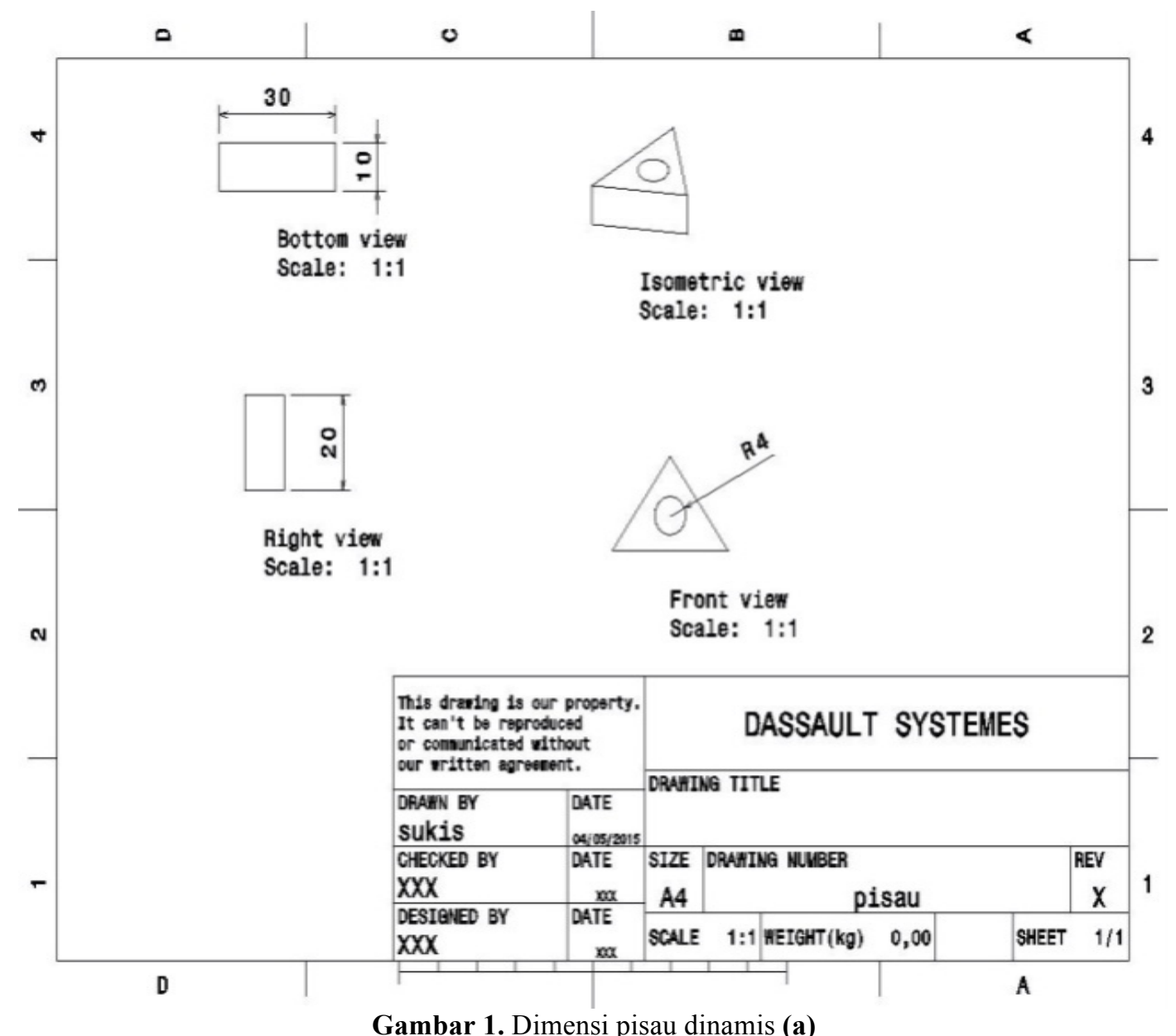

Gambar 1. Dimensi pisau dinamis (a) 
Teknik, 37 (1), 2016, 4

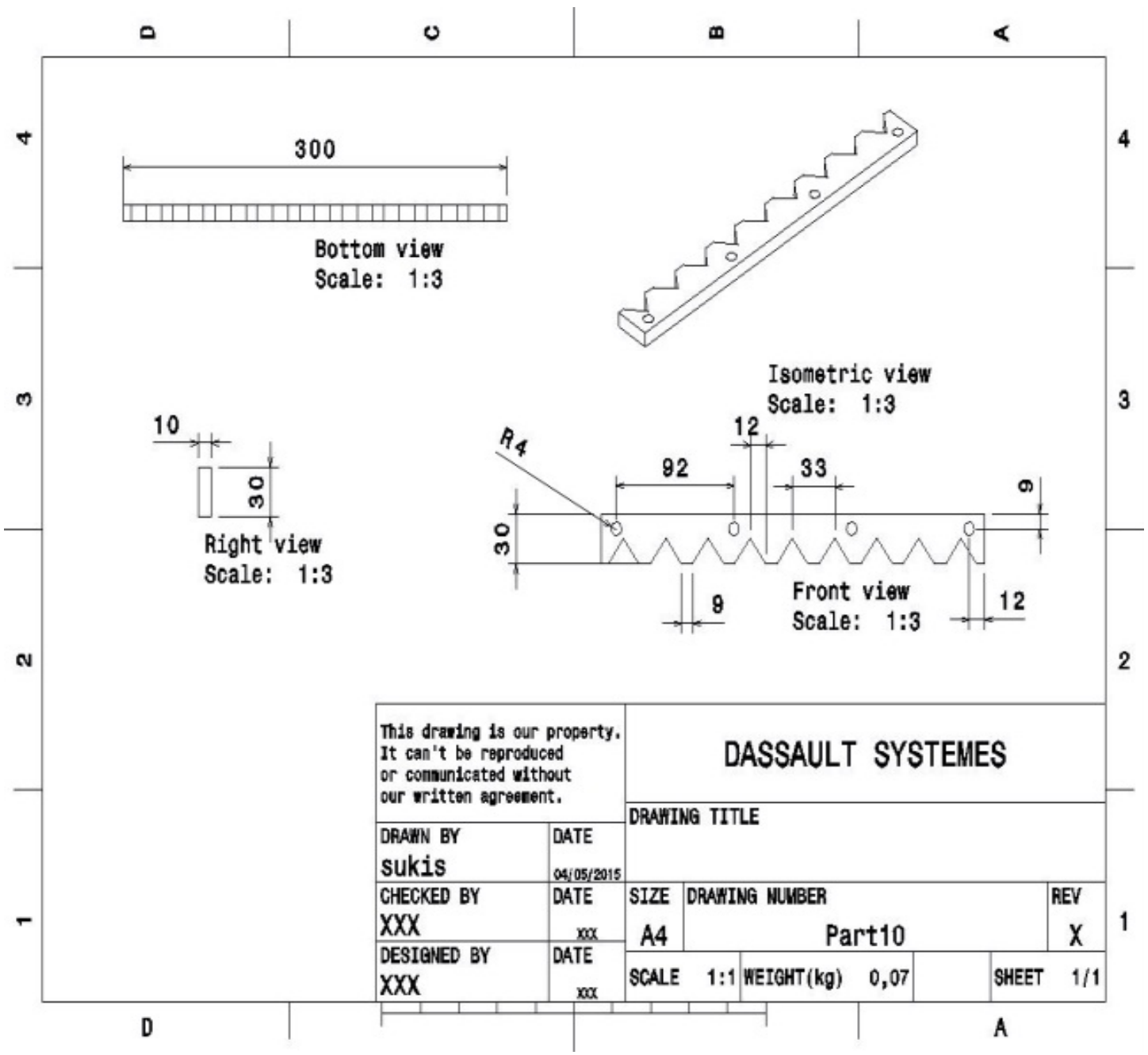

Gambar 1. Dimensi pisau dinamis (b)

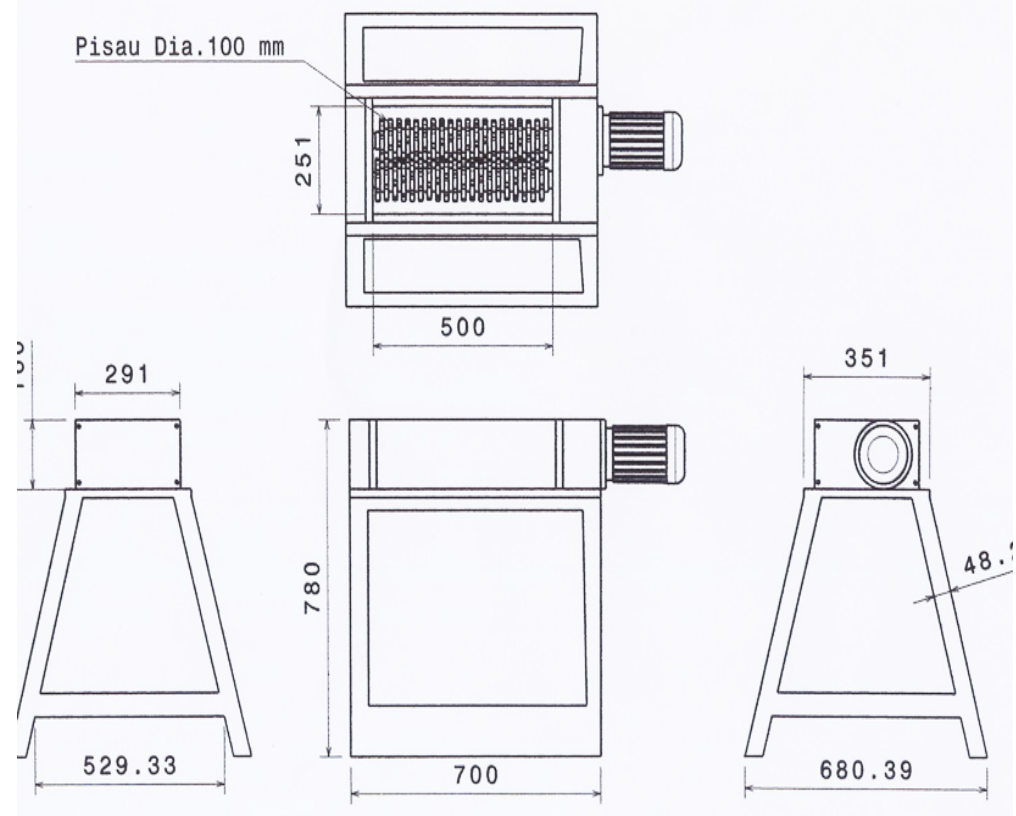

Gambar 2. Ukuran dan dimensi rancangan alat 


\section{Teknik, 37 (1), 2016, 5}

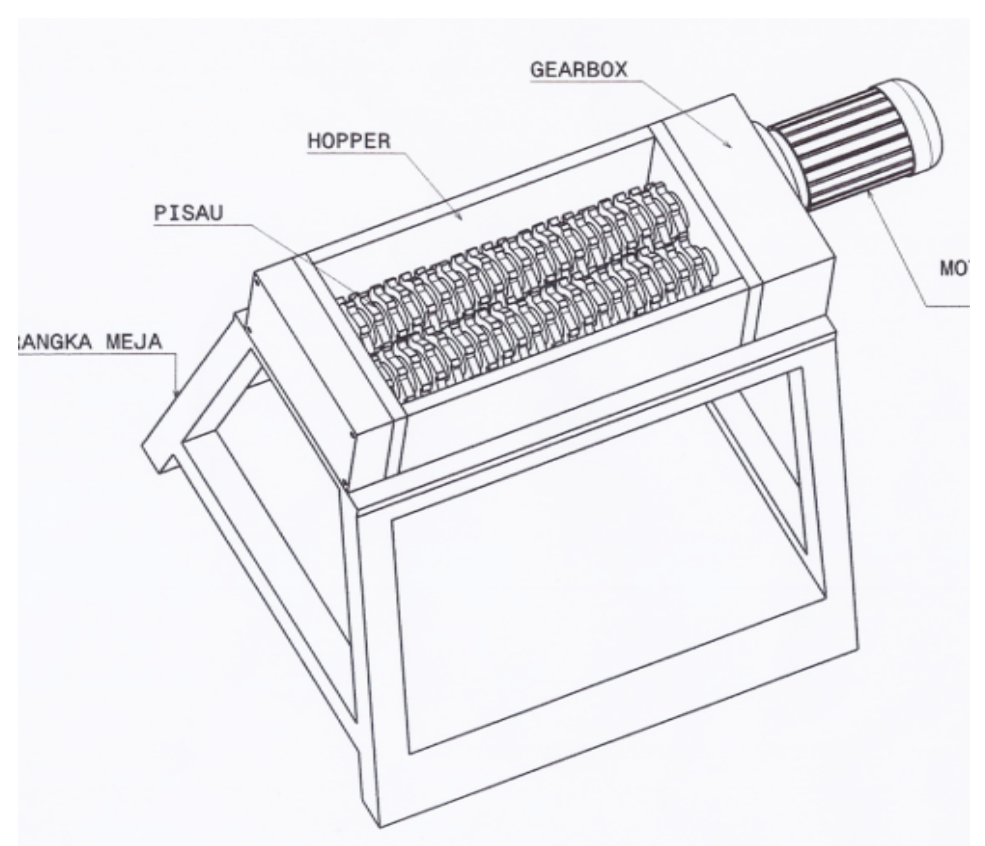

Gambar 3. bagian-bagian rancangan alat.

Kegiatan penelitian ini dilaksanakan di Laboratorium Teknik Mesin Universitas Muria Kudus dan UMKM Industri eternit desa Loram Kudus. Hal yang perlu diperhatikan dalam proses perancangan teknik meliputi desain, faktor kekuatan,faktor ergonomi, kebutuhan bahan serta faktor biaya (Ruswandi, 2004). Untuk melaksanakan program penerapan dan pengembangan teknologi ditunjukkan pada diagram alir Gambar 4.

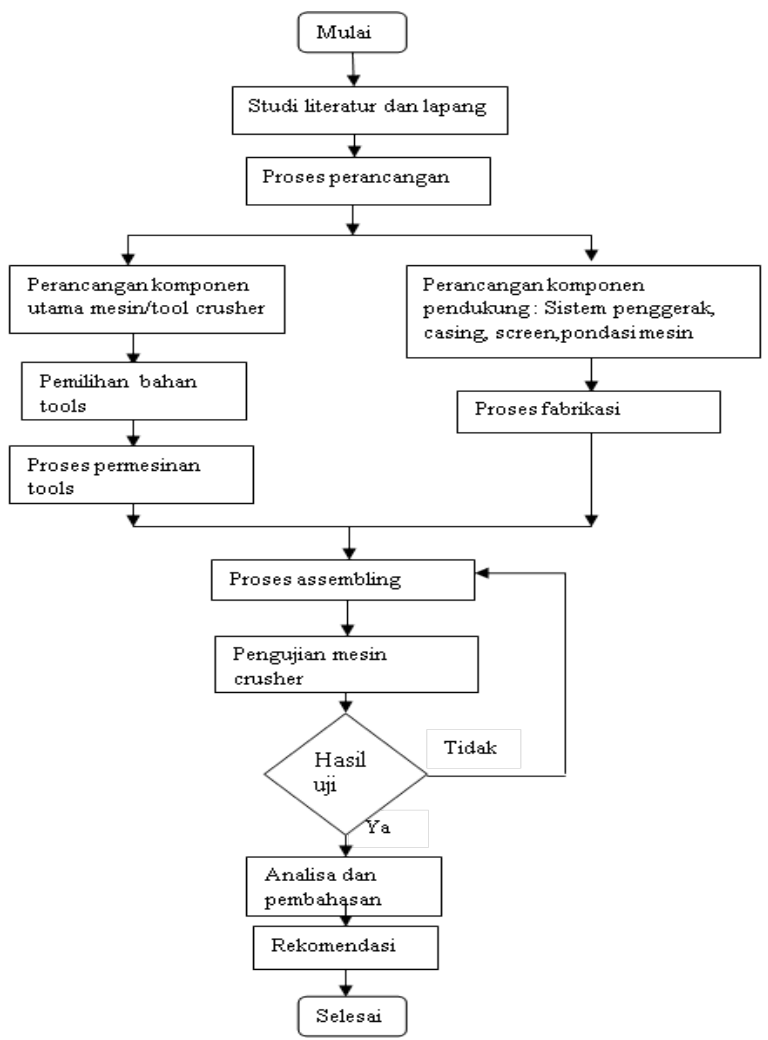

Gambar 4. Alur pembuatan mesin perajang kain.

\section{Hasil dan Pembahasan}

Dari pengamatan di lapangan, pekerjaan pembuatan eternit membutuhkan serat penguat untuk bahan baku pembuatan eternit yang diperoleh dari limbah kain pabrikan, berdasarkan hal tersebut kami merancang bangun mesin pengolah limbah kertas dan kain menjadi bahan baku eternit untuk produksi UKM eternit dengan kapasitas 1200 gr/putaran (Gambar 5). Tenaga penggerak menggunakan motor listrik 6 PK, 3 phase putaran $1400 \mathrm{rpm}$, sehingga kapasitas maksimal mesin crusher sebesar $120 \mathrm{~kg} / \mathrm{jam}$.

Pada Gambar 5, material pisau menggunakan baja special $\mathrm{K}$ dengan proses pengerasan hardening sebagai berikut: Suhu hardening 950-980 ${ }^{\circ} \mathrm{C}$ untuk mencapai kekerasan 63-65 RC media quenching oli atau udara. Untuk mencapai suhu $950{ }^{\circ} \mathrm{C}$ harus dipanaskan bertahap yaitu: (1). Suhu 450 ditahan selama 10 menit / 10 mm tebal material; (2). Lalu dipanaskan lagi ke 750 ${ }^{\circ} \mathrm{C}$ selama 10 menit / $10 \mathrm{~mm}$ tebal material; (3). Lalu dipanaskan kembali sampai suhu $950-980{ }^{\circ} \mathrm{C}$; (4). Di tahan sebentar lalu di keluarkan dan di celupkan ke dalam oli quenching sambil digoyanggoyang supaya gelembung asap cepat terlepas dari permukaan baja sehingga pendinginannya dapat merata.

Adapun sisi mata potong pada pahat mempunyai $15 \mathrm{~mm}^{3}$ sama artinya dengan volume serat kain yang terpotong. Massa serat kain dengan memilih salah satu jenis serat kain misalnya serat kapas $\rho=1,49 \frac{\mathrm{g}}{\mathrm{cm} 3}$ maka didapatkan kapasitas mesin crusher sebanyak 1200 gr/putaran. Tenaga penggerak menggunakan motor listrik $6 \mathrm{PK}, 3$ phase putaran $1400 \mathrm{rpm}$, sehingga kapasitas maksimal mesin crusher sebesar $120 \mathrm{~kg} / \mathrm{jam}$. 
Teknik, 37 (1), 2016, 6

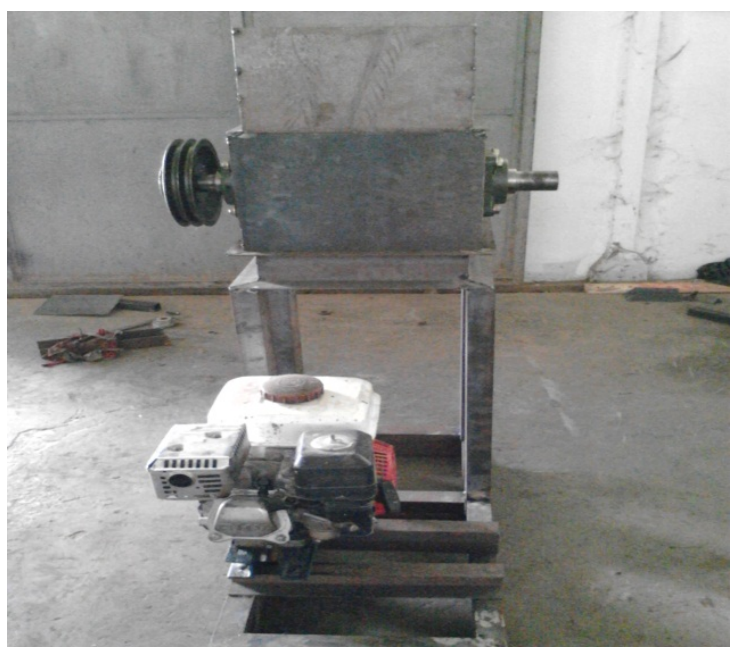

(a)

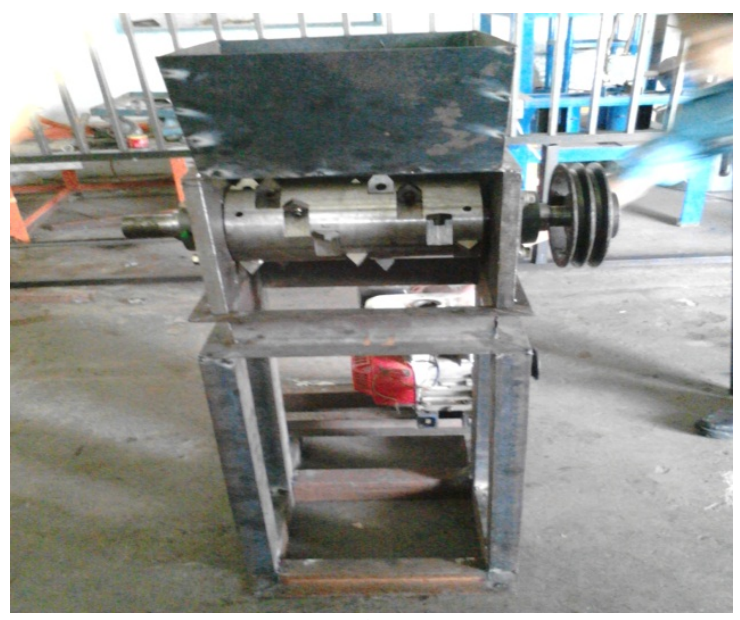

(b)

Gambar 5. Bentuk mesin dari dua sisi.

\section{Kesimpulan}

Telah dirancang mesin pengolah limbah kertas dan kain dengan kapasitas mesin crusher sebanyak 1200 gr/putaran, sebagai bahan baku eternit untuk meningkatkan kapasitas produksi industri eternit. Rancangan mesin pengolah limbah kertas dan kain sebagai bahan baku eternit, dan direncanakan kemampuan tenaga penggerak menggunakan motor listrik 6 PK, 3 phase putaran 1400 rpm, sehingga kapasitas maksimal mesin crusher sebesar $120 \mathrm{~kg} / \mathrm{jam}$.

\section{Ucapan Terima Kasih}

Terima kasih disampaikan kepada DP2M DIKTI yang telah member pendanaan dalam penelitian ini, juga Laboratorium Teknik Universitas Muria Kudus dan UMKM Industri eternit desa Loram Kudus yang telah member fasilitas dalam proses pembuatan rancang bangun mesin pengolah limbah kain dan kertas.

\section{Daftar Pustaka}

Ruswandi, A. (2004). Metoda Perancangan, Bandung, Politeknik Manufaktur Negeri Bandung.

Malau, V. (2004). Diktat Teknologi Bahan. Yogyakarta: Teknik mesin, UGM.

Hendro, S. (2011). Perlakuan Panas Pada Baja. Solo: ATMI.

Fauji R. (2011). Uji Pembakaran dan Uji Berat Jenis Serat Kain. Bandung: Sekolah Tinggi Teknologi Tekstil.

Harsokoesoma, H. Darmawan. (2004). Pengantar Perancangan Teknik (Perancangan Produk). Bandung: Politeknik Manufaktur Negeri Bandung..

Sularso, Kiyokatsu Suga. (1991). Dasar Perencanaan dan Pemilihan Elemen Mesin. Jakarta: Pradnya Paramita.

Sularso, Kiyokatsu Suga. (1997). Dasar Perencanaan dan Pemilihan Elemen Mesin. Jakarta: Pradnya Paramita.

Curtis Johnson. (1993). Process Control Instrumentation Technology, 4th Edition, Prentice Hall International Inc, New Jersey.

Deutchman, Aaron, D. (1975). Machine Design: Theory And Practice, Macmillan Publishing Co Inc., New York.

Eckman, P, Donald. (1995). Industrial Instrumentaion.New York: John Willey \& Sons Inc.

Kollman, F. F. P. E. W, Kuenzi, A. J Stamm, 1975, Principles of Wood Science and Technology II, Springer-Verlag Berlin Heidelberg New York. 